\title{
Experimental analysis of the spreading of a liquid film on a bipropellant thruster chamber wall
}

\author{
Noritaka SAKO*, Jun HAYASHI*, Yu DAIMON**, Hiroumi TANI** and Hiroshi KAWANABE* \\ *Department of Energy Science, Kyoto University \\ Yoshida Honmachi, Sakyo-ku, Kyoto 606-8501, Japan \\ E-mail: sako.noritaka.32c@st.kyoto-u.ac.jp \\ ${ }^{* *}$ Research Unit III, Research and Development Directorate, Japan Aerospace Exploration Agency \\ 2-1-1 Sengen, Tsukuba, Ibaraki 305-8505, Japan
}

Received: 13 April 2020; Revised: 25 May 2020; Accepted: 24 June 2020

\begin{abstract}
In film cooling approaches, a film of liquid fuel is formed on the chamber wall of bipropellant thrusters to protect the chamber wall from high-temperature combustion gases. To optimize the amount of liquid fuel required to sufficiently cool a chamber wall in this manner without degrading the performance of bipropellant thrusters, the formation process of the liquid film needs to be understood. To this end, in this study, factors affecting the spread of liquid film were experimentally investigated. In particular, experimental apparatus that could reproduce the state of a liquid jet being injected onto a wall to form a liquid film was developed. Water was used as the test liquid because hydrazine-derivative fuels, which are generally used in bipropellant thrusters, are toxic, and the density and surface tension of water are similar to those of hydrazine. The liquid film formation processes were visualized and analyzed by using a still camera. Results indicated that the liquid jet velocity, nozzle diameter, and impingement angle were the key factors affecting the film width, and the maximum film width exhibited a linear relation to the liquid jet velocity component perpendicular to the wall. Considering these results, a general relationship between the key factors and maximum film width was identified, and it was noted that the dimensionless maximum film width could be defined as the product of the Weber number and sine value of the impingement angle. In this manner, the maximum film width can be predicted when deciding injection conditions, which can assist thruster designers during the design process.
\end{abstract}

Keywords : Bipropellant thruster, Liquid film cooling, Visualization, Film spread, Weber number

\section{Introduction}

Bipropellant thrusters, which are used for the attitude control and orbit maneuvering of satellites and small spacecraft, are operated using both steady-state and pulse-mode firing with firing times ranging from $O(10) \mathrm{ms}$ to $O(1) \mathrm{s}$. In such thrusters, a combination of a hydrazine-derivative fuel (e.g. hydrazine $\left(\mathrm{N}_{2} \mathrm{H}_{4}\right)$, monomethylhydrazine (MMH and $\mathrm{CH}_{3} \mathrm{NHNH}_{2}$ ), unsymmetrical dimethylhydrazine (UDMH and $\left.\left(\mathrm{CH}_{3}\right)_{2} \mathrm{NNH}_{2}\right)$ ), and nitrogen tetroxide (NTO) is employed as a propellant. These combinations of fuels and oxidizer are hypergolic (Sutton and Biblarz, 2016; Davis and Yilmaz, 2014), which means that they ignite immediately after contacting each other without ignition devices, even at low pressures and temperatures (Webber and Hoffman, 1972; Iihara et al., 1987; Matsuura et al., 2013). To exploit the hypergolicity condition, unlike-impingement type injectors are generally employed in bipropellant thrusters (Sutton and Biblarz, 2016). The injector and chamber are carefully designed to achieve a high performance in the steady-state mode and fast ignition response in the pulse mode. However, the development of thrusters primarily relies on the conduction of multiple cost- and time-intensive tests, as numerical models of the multi-physics phenomena occurring in the combustion chamber remain insufficient in terms of the in-depth understanding of such phenomena.

In particular, hypergolic combustion via impinging jet involves the following phenomena: impinging atomization and spray formation (Webber and Hoffman, 1972), liquid phase reaction near the impingement point (Iihara et al., 1987), droplet burning (Matsuura et al., 2013; Chen et al., 2012) and gas phase reactions (Dambach et al., 2013; Lawver, 1966; 
Lawver and Breen, 1967). Owing to the high temperature of the combustion gases, it is necessary to protect the chamber wall from the core flow. Therefore, bipropellant thrusters generally employ a film cooling technique (Daimon et al., 2017), in which a part of the fuel is injected onto the combustion chamber wall to form a liquid film to prevent the wall surface from being exposed to the high-temperature combustion gases. Figure 1 shows a schematic of liquid film cooling performed using liquid fuel. It can be noted that the generated film heats up and evaporates because of the combustion gas and heat input from the combustion chamber wall. As the evaporated film reacts with the gashouse oxidizer in the mainstream and influences the combustion efficiency and thrust performance, it is necessary to optimize the amount of fuel used for film cooling to achieve sufficient cooling and maintain a high performance.

Liquid film cooling in the combustion chambers of rocket engines has been investigated. Stechman et al. (1969) suggested analytical models for film cooling and proposed a formula to predict the film cooling length of the liquid phase. The convective heat transfer from the main stream to the liquid film and the heat loss through the chamber wall were considered using a modification of the Bartz equation (Bartz, 1957) to calculate the turbulent heat transfer coefficient. Recently, Shine et al. (2012) examined the prediction of the liquid film length via theoretical analyses and developed a one-dimensional analytical model incorporating all the known phenomena for liquid film cooling in a rocket combustion chamber operating in the subcritical state. It is necessary to calculate the liquid film length to predict the temperature distribution of the chamber walls. However, the spatial distribution of the liquid film cannot be considered using the onedimensional model. In film cooling processes, the heat inputs from the combustion gases and chamber wall are transformed into sensible heat and latent heat. Consequently, the cooling characteristics are affected by the wetting area, that is, the width, length, and thickness of the film.

In addition, several researchers have attempted to determine the spatial distribution of a liquid film under non-heat input conditions. Morison and Thorpe (2002) provided experimental data for the wetting of a surface by a liquid jet of water and various aqueous solutions. Wilson et al. (2012) developed a model of liquid films, taking into account the mass flow rate, viscosity, surface tension, contact angle, density, and gravity. This model could be used to predict the wetted width and radius of hydraulic jump, which occurs when the momentum of the radially outward flow is balanced by surface tension, and the results were noted to be in good agreement with the experimental data reported by Morison and Thorpe (2002). These studies focused on the film formed by a single jet vertically impinging on a surface. Wang et al. (2013) investigated the flow patterns by changing the impingement angle and modified Wilson's model to include the effect of the impingement angle. Good and Nollet (2017) investigated the fluid film distribution for conditions involving an extremely low flow rate $(<7 \mathrm{~g} / \mathrm{s})$, small nozzle diameter $(<2 \mathrm{~mm})$, and small impingement angle $\left(<25^{\circ}\right)$, and observed that a linear relationships existed between the maximum film width and fluid velocity. However, the spatial distribution of a liquid film under such conditions in the range of the operating conditions of actual bipropellant thrusters remains unclear.

Moreover, the fuel used for film cooling is injected from the outermost injection holes of the face plate, as shown in Fig. 2, with the design parameters including the interval between the injection holes, nozzle diameter, impingement angle, and distance from the face plate to the plate (i.e. liquid jet length). Therefore, it is important to predict the film width with respect to the injection conditions when deciding these parameters. However, the design of the face plate is determined based on the results obtained by performing many experimental tests, which requires a large amount of cost and time in the development stage. Therefore, it is desirable to realize the design process on the basis of understanding the physical phenomena.

Consequently, in this study, to understand the formation processes of a liquid film, experiments were conducted under conditions involving a low flow rate, small nozzle diameter, and small impingement angle, with values similar to the design values of the face plate used in bipropellant thrusters. In addition, the effect of the liquid jet length on the film width was investigated, and an experimental analysis pertaining to the spread of liquid film was performed.

\section{Experimental apparatus}

In actual bipropellant thrusters, the liquid films injected from multiple injection holes may interfere among one another. However, in this study, the liquid film formed by a single liquid jet was considered to understand the film formation process in detail. An experimental apparatus that could stimulate the method of film formation from a single hole was developed, as shown in Fig. 3. The experimental apparatus consisted of an injector part imitating a single injection hole, a metal plate simulating the chamber wall, an imaging system, and a liquid supply system. 


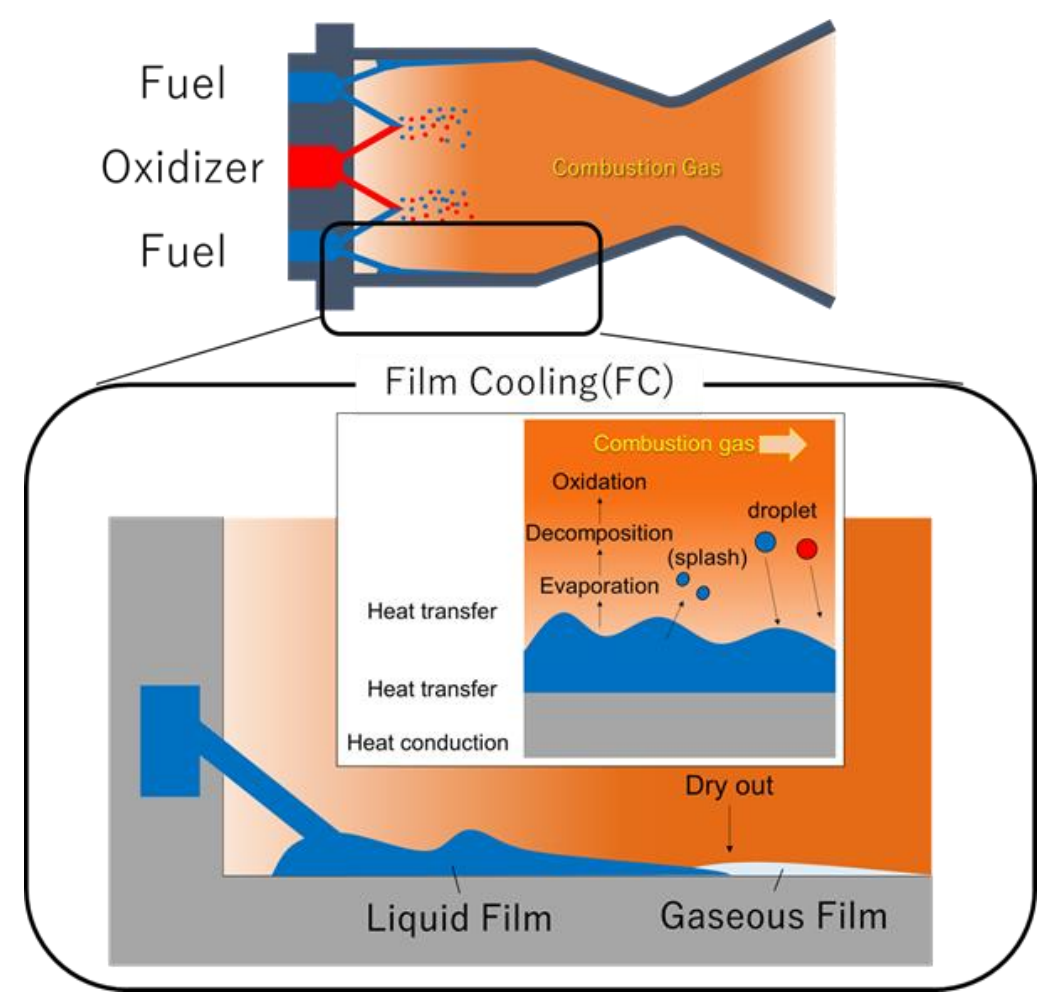

Fig. 1 Schematic of film cooling of a bipropellant thruster.

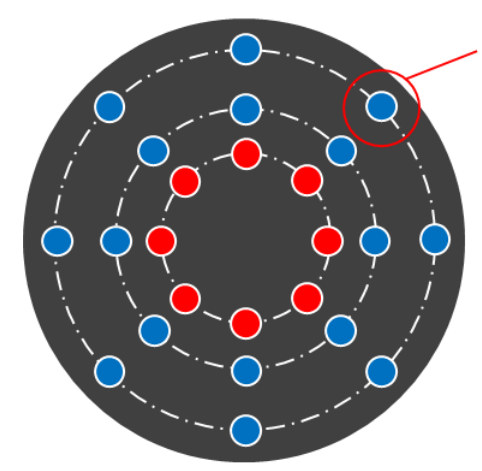
Nozzle of liquid fuel for film cooling Parameters

- Injection flow rate

- Nozzle diameter

- Impingement angle

- Fluid jet length etc.

Fig. 2 Schematic of the face plate.

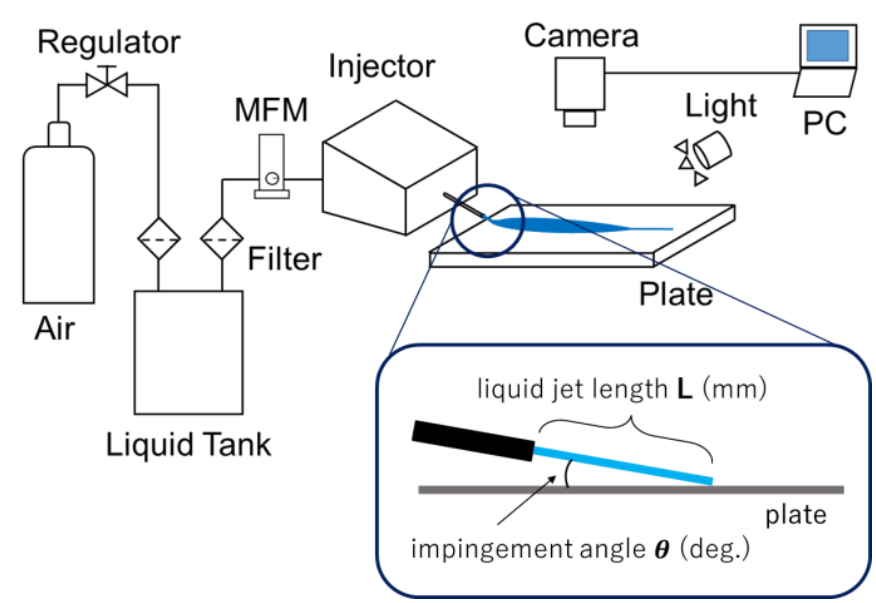

Fig. 3 Schematic of the experimental apparatus. 
In the injector part, straight type nozzles with different diameters could be employed to evaluate the effect of the nozzle diameter on the film formation. Nozzle diameter of $0.7 \mathrm{~mm}$ and $1.12 \mathrm{~mm}$ were considered, which lie in the design range of the actual face plate. The state of the edge of the nozzle exit was that the pipe was only cut, and the radial thickness of both nozzles was $0.18 \mathrm{~mm}$. The injector part was set on a three-axis traverse system and a goniometer stage to investigate the effects of the liquid jet length (i.e., the distance between the nozzle and impingement point) and impingement angle on the film formation. The liquid jet length and impingement angle could be adjusted within the design range. On the three-axis traverse system, the injector part could be moved $\pm 6.5 \mathrm{~mm}$ and $\pm 5 \mathrm{~mm}$ on the $\mathrm{XY}$ and $\mathrm{Z}$ axes, respectively, with a least count of $0.01 \mathrm{~mm}$. The dimensionless liquid jet length, that is, the ratio of the liquid jet length to the nozzle diameter was set as $6,8,10$, and 20. Although the value of 20 was beyond the design range, the test was conducted to investigate the effect of the liquid jet length in detail. The goniometer could be adjusted in the angle range of $\pm 20^{\circ}$, and the least count was $0.1^{\circ}$. The impingement angle was varied from $10^{\circ}$ to $25^{\circ}$ in increments of $5^{\circ}$.

Water was used as the test liquid instead of liquid fuels, as hydrazine-derivative fuels are toxic, and the density and surface tension of water are similar to those of hydrazine, which make water a suitable test liquid to investigate the film spread phenomenon. In the experiments, water was pressurized by air in the test liquid tank, as shown in Fig. 3, and injected from the nozzle. The mass flow rate was varied from $3.0 \mathrm{~g} / \mathrm{s}$ to $6.0 \mathrm{~g} / \mathrm{s}$ in increments of $1.0 \mathrm{~g} / \mathrm{s}$ by using a mass flow mater with a needle valve. A flat plate of stainless steel was used to imitate the chamber wall because the area where a liquid film was formed with respect to the circumference of combustion chamber wall was small. The surface of the plate was polished with \#400 buffing. The experimental conditions are listed in Table 1. The behavior of the film spreading was observed by using a camera (Baumer VCGX-124M) to perform imaging from the top of the plate. A bright metal halide lamp (Sumita optical glass LS-350) was selected as a light source. The resolution and exposure time were $31 \mu \mathrm{m} /$ pixel and $20 \mathrm{~ms}$, respectively. Figure 4 shows an example of the film image recorded using the imaging system. Specifically, using this imaging system, the state in which a liquid jet impinges to the wall obliquely and forms a liquid film could be observed. The distance from the impingement point was defined as $x$, and the half film width at each $x$ was $w / 2$. The maximum half film width at each condition was defined as $(w / 2)_{\max }$. The half film width value was considered because the light irradiated obliquely from above, and the film width could be measured accurately by taking into account the brightness of the outer edge of the film on the light source side. Furthermore, the film shape was symmetric, as shown in Fig. 4, and only the half value of the film width was thus required to be considered.

Table 1 Experimental conditions.

\begin{tabular}{|c|c|c|}
\hline Mass flow rate, $m$ & {$[\mathrm{~g} / \mathrm{s}]$} & $3.0,4.0,5.0,6.0$ \\
\hline Nozzle diameter, $D$ & {$[\mathrm{~mm}]$} & $0.7,1.12$ \\
\hline Dimensionless length of liquid jet, $L / D$ & {$[-]$} & $6,8,10,20$ \\
\hline Impingement angle, $\theta$ & {$\left[{ }^{\circ}\right]$} & $10,15,20,25$ \\
\hline
\end{tabular}

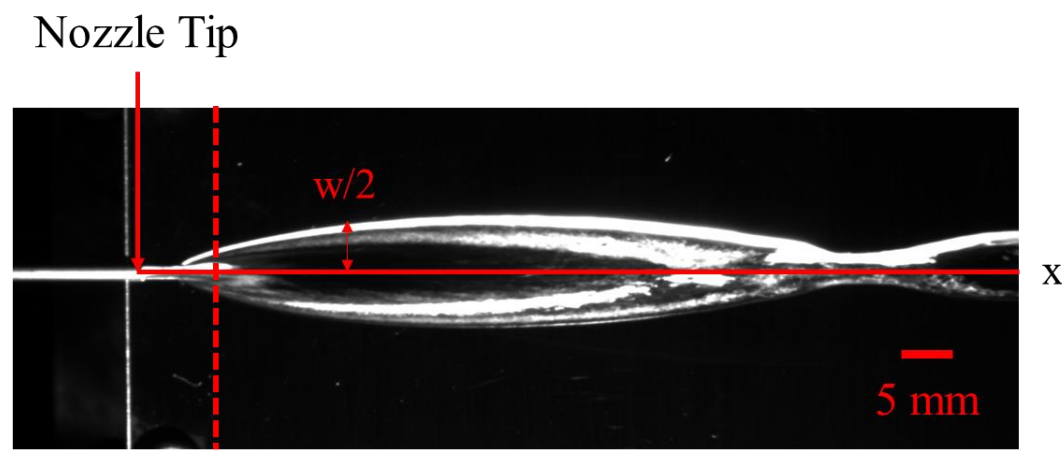

Impingement Point $(\mathrm{x}=0)$

Fig. 4 Direct image of film and defined values. 


\section{Results and discussion}

\subsection{Formation process of liquid film}

In particular, a liquid film spreads owing to the momentum in the direction of spread immediately after the liquid jet impinges onto the wall, and subsequently, the film shrinks because of the surface tension. The shape of the film is a result of the balance between the inertia of the liquid film and surface tension.

When a liquid jet is injected from a nozzle to stationary air, the unstable waves on the surface of the liquid jet grow owing to the interfacial instability, and a breakup of the liquid jet occurs. It is likely that the growth of the unstable waves before impingement of the liquid jet onto the wall affects the film formation. Therefore, the effect of $L / D$ on the film formation was investigated, where $L$ and $D$ represent the liquid jet length and nozzle diameter, respectively. The impingement angle was fixed as $10^{\circ}$, and the nozzle diameter was set as $0.7 \mathrm{~mm}$ and $1.12 \mathrm{~mm}$ to investigate the effect of the nozzle diameter. Figure 5 shows the direct images of the film at each $L / D$ condition with $D=0.7 \mathrm{~mm}$. As the value of $L / D$ increased, droplets were noted to form around the impingement point. These droplets were thought to be a desecrated from the liquid jet surface owing to the instability on the liquid surface. The deformation on the surface of the liquid jet increased with an increase in the distance to the impingement point $(L)$. However, the film shape did not significantly change with a change in the $L / D$ value. Figures 6 and 7 show the values of $w / 2$ at each $x$ for each $L / D$ value under the conditions of $D=0.7 \mathrm{~mm}$ and $1.12 \mathrm{~mm}$. No significant difference in the film width was observed. The breakup length of the inviscid liquid jet, $L_{\mathrm{b}}$, can be expressed as in Eq. (1) (Strutt and Rayleigh, 1878; Weber, 1931).

$$
\frac{L_{\mathrm{b}}}{D}=1.04 C \sqrt{W e}
$$

The Weber number can be expressed as follows.

$$
W e=\frac{\rho V_{0}^{2} D}{\sigma}
$$

where $V_{0}, \rho$ and $\sigma$ denote the liquid jet velocity, the density and surface tension coefficient of the liquid, respectively. The value of $V_{0}$ was obtained by dividing each mass flow rate by the density and cross-sectional area of the liquid jet. In Eq. (1), $C$ indicates the disturbance factor, and a value of $C=13$ was used in the case of low-viscosity liquid jets, according to Grant and Middleman (1966). Because the experimental conditions in this work involved $W e=143$ to 2438 , the breakup length of the liquid jet was calculated as $L_{\mathrm{b}} / D>162$ by using Eq. (1). The tests were conducted

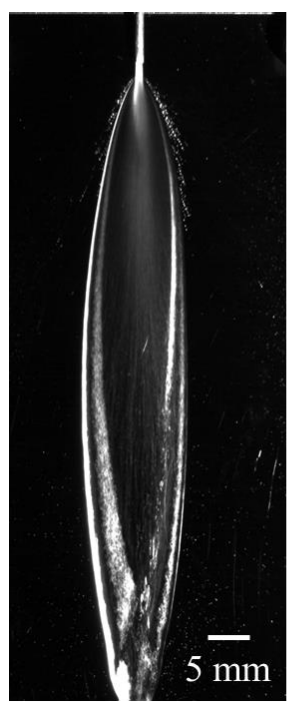

(a) $L / D=6$

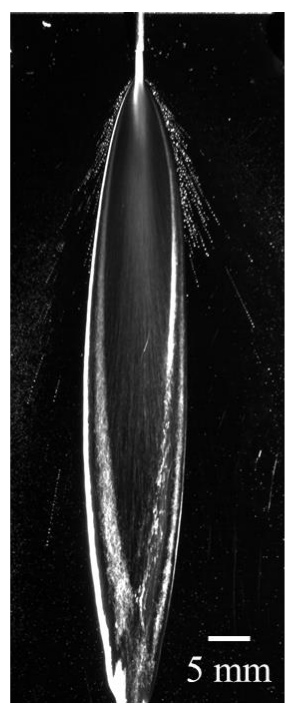

(b) $L / D=8$

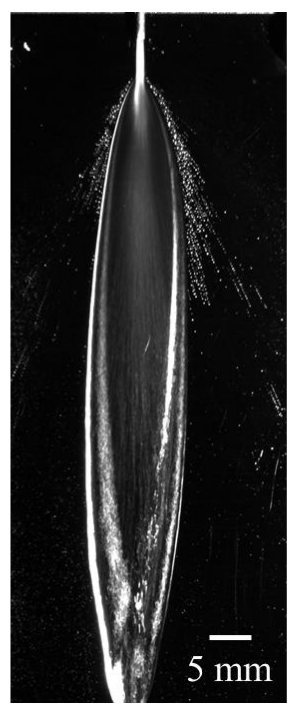

(c) $L / D=10$

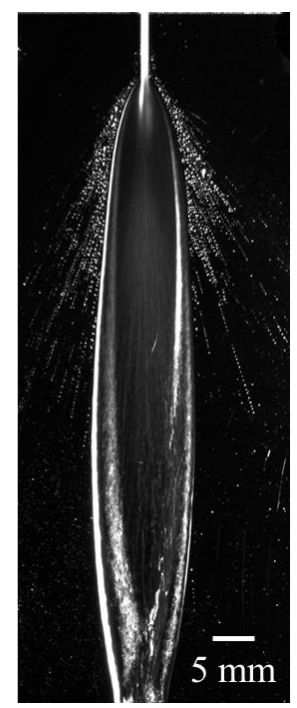

(d) $L / D=20$

Fig. 5 Effect of liquid jet length on the film spread under a nozzle diameter of $0.7 \mathrm{~mm}$. 


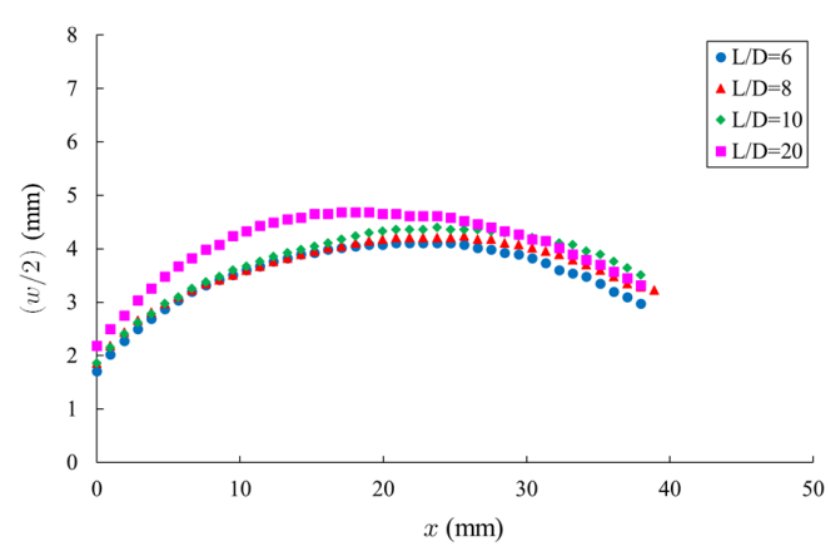

(a) $m=3.0 \mathrm{~g} / \mathrm{s}$

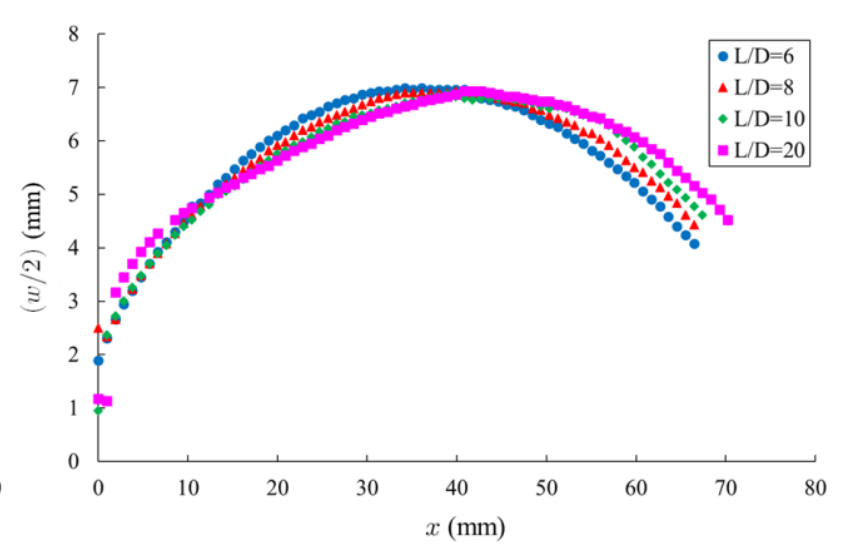

(b) $m=6.0 \mathrm{~g} / \mathrm{s}$

Fig. 6 Effect of liquid jet length on film width at $D=0.7 \mathrm{~mm}$

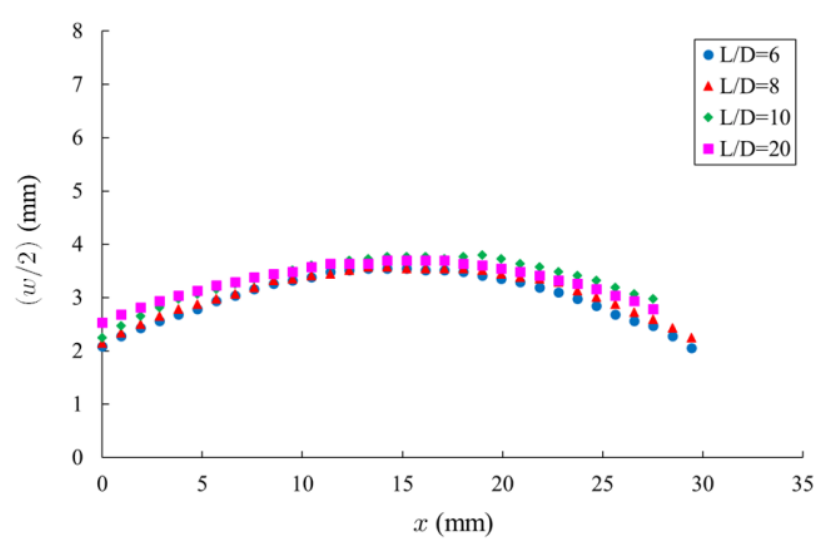

(a) $m=3.0 \mathrm{~g} / \mathrm{s}$

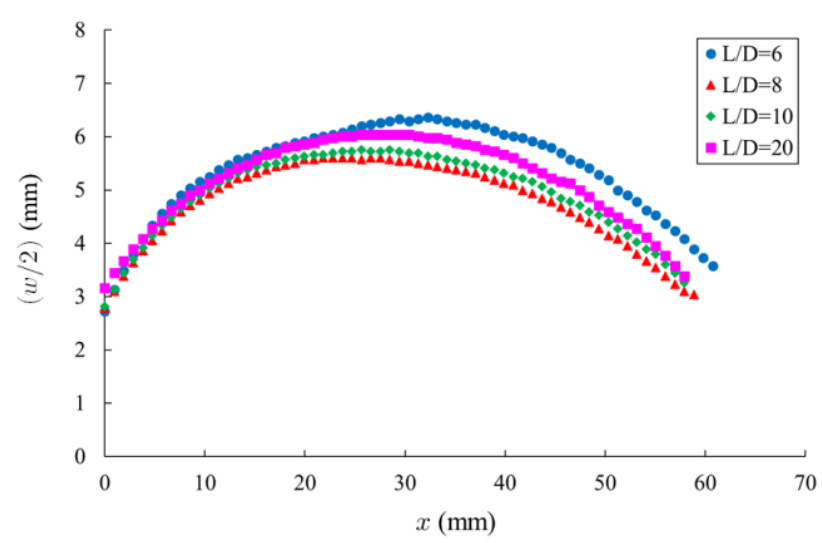

(b) $m=6.0 \mathrm{~g} / \mathrm{s}$

Fig. 7 Effect of liquid jet length on film width at $D=1.12 \mathrm{~mm}$

with $L / D$ ranging from 6 to 20, and the growth of the instability on the surface of the liquid jet was considered to be small. Furthermore, the transition Reynolds number of a pipe flow is well known as approximately 2300 . In the experimental conditions in this work, $R e=3387$ to 10839 ; therefore, the liquid jets were likely turbulent flows. Consequently, the value of $L / D$ in this study was compared with the breakup length of the liquid jet in the turbulence region. According to Grant and Middleman (1966), the breakup length of the liquid jet under a turbulent region was expressed as in Eq. (3).

$$
\frac{L_{\mathrm{b}}}{D}=8.51(\sqrt{W e})^{0.64}
$$

Using Eq. (3), it was calculated that $L_{\mathrm{b}} / D>41$. Therefore, it was considered that the growth of the instability of the liquid jet was small, and the film formation was not affected even if the liquid jet transitioned to the turbulent region. These results indicated that the liquid jet length did not affect the film formation when the value of $L / D$ was within the range of the considered experimental conditions and the design range of actual thrusters.

Figure 8 shows the images of the films formed under different conditions of the mass flow rate and nozzle diameter, with the impingement angle fixed as $10^{\circ}$. As shown in Figs. 8 (a) and (b) (or (c) and (d)), the width and length of the film, which was defined as the distance from the impingement point to the point where the liquid film shrank to the width at impingement point, increased with an increase in the mass flow rate because the liquid jet velocity increased with the mass flow rate. In addition, comparing Figs. 8 (a) and (c) (or (b) and (d)), no significant difference was noted between 
the film width pertaining to $D=0.7 \mathrm{~mm}$ and $1.12 \mathrm{~mm}$. Furthermore, the length of the film in the case of $D=0.7 \mathrm{~mm}$ was larger than that when $D=1.12 \mathrm{~mm}$ under the same mass flow conditions, especially for the lower mass flow rates, because the liquid jet velocity of $D=0.7 \mathrm{~mm}$ was higher than that for $D=1.12 \mathrm{~mm}$ under the same conditions of the mass flow rate.

Figure 9 shows the relationship between $V_{0}$, and $(w / 2)_{\max }$ under each nozzle diameter condition. The mass flow rate was set as 3.0, 4.0, 5.0, and $6.0 \mathrm{~g} / \mathrm{s}$. The results shown in Fig. 9 correspond to the average values of $(w / 2)_{\max }$ obtained by testing three times for each mass flow rate condition. It was noted that $(w / 2)_{\max }$ increased with an increase in $V_{0}$. In addition, a linear relationship existed between $V_{0}$ and $(w / 2)_{\max }$ at each nozzle diameter condition, as reported by Good and Nollet (2017), although the slope differed depending on the nozzle diameter. This finding suggested that the nozzle diameter was a critical factor that affected the spread of a liquid film.

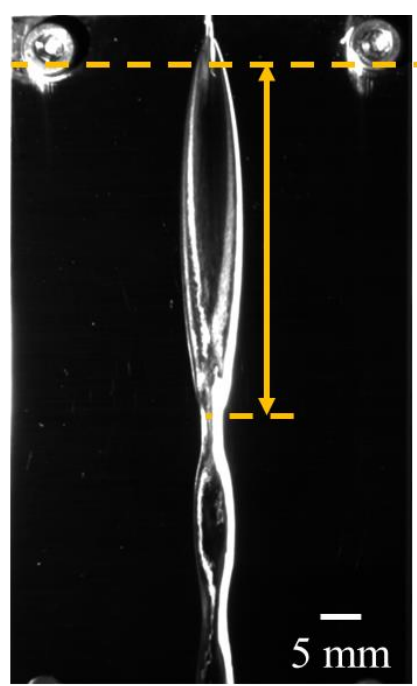

(a) $D=0.7 \mathrm{~mm}$ and $m=3.0 \mathrm{~g} / \mathrm{s}$

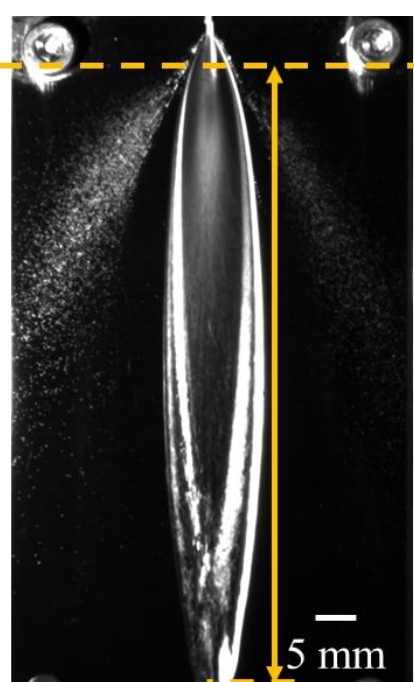

(b) $D=0.7 \mathrm{~mm}$ and $m=6.0 \mathrm{~g} / \mathrm{s}$

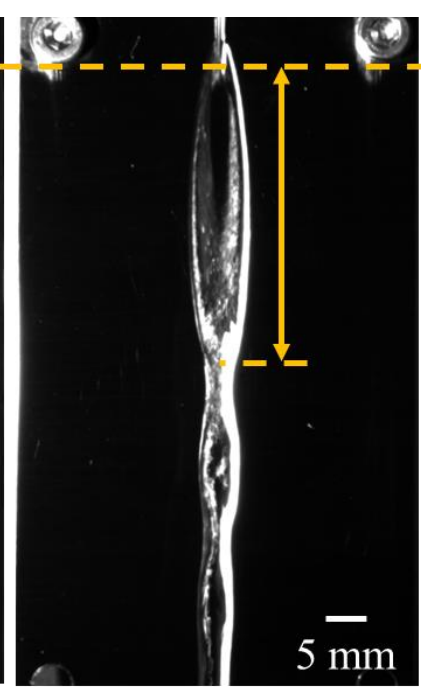

(c) $D=1.12 \mathrm{~mm}$ and $m=3.0 \mathrm{~g} / \mathrm{s}$

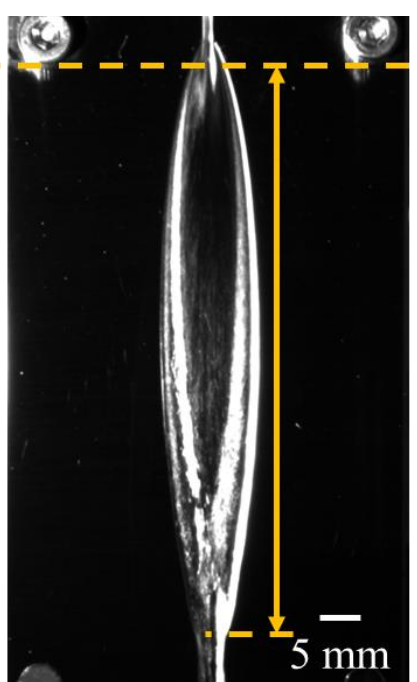

(d) $D=1.12 \mathrm{~mm}$ and $m=6.0 \mathrm{~g} / \mathrm{s}$

Fig. 6 Film spreading under different conditions of mass flow rate and nozzle diameter.

The impingement points were on the upper broken line, and two direction arrows indicated the length of the film under each condition.

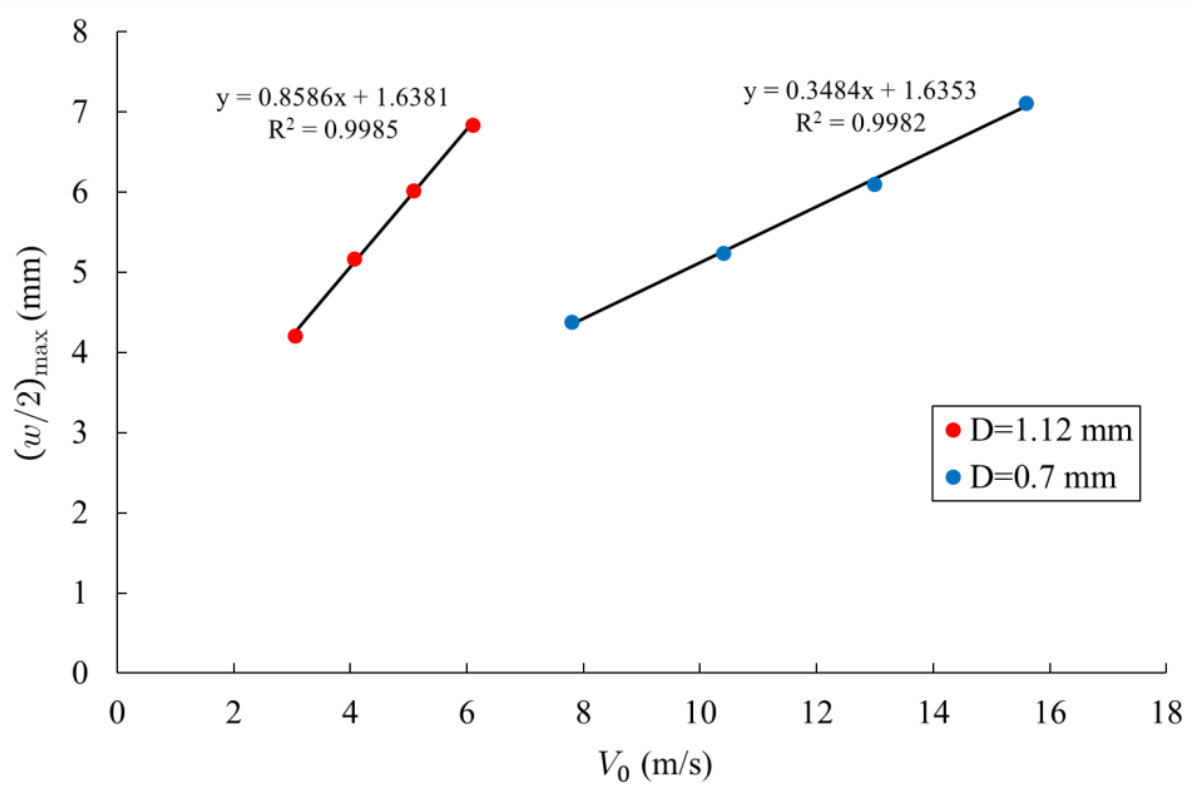

Fig. 7 Effect of nozzle diameter on the maximum film width. 
Figure 10 shows the images of the film recorded at each impingement angle condition. The nozzle diameter was 1.12 $\mathrm{mm}$, and the mass flow rate was set as $5.0 \mathrm{~g} / \mathrm{s}$. It can be noted from Fig. 11, which shows the relationship between $V_{0}$ and $(w / 2)_{\max }$ under each condition of the nozzle diameter and mass flow rate, that the film width increased as the impingement angle increased. Furthermore, the parameters exhibited a linear relationship under all the impingement angle conditions. However, the film length downstream decreased as the impingement angle increased, as shown in Fig 10. These findings pertaining to the width and length of the film indicated that the component of the liquid jet velocity perpendicular to the wall (i.e., $V_{0} \sin \theta$, where $\theta$ is the impingement angle, as shown in Fig. 3) contributed to the film width, and the horizontal component (i.e., $V_{0} \cos \theta$ ) contributed to the length. Figure 12 shows the relationship between $V_{0} \sin \theta$ and $(w / 2)_{\max }$. Under each nozzle condition, the results under different angles shown in Fig. 11 corresponded to those pertaining to $V_{0} \sin \theta$, and linear relationships between $V_{0} \sin \theta$ and $(w / 2)_{\max }$ were observed under each condition of the nozzle diameter.

\subsection{Film width characterization}

To identify the relationship between $(w / 2)_{\max }$ and the key factors under various conditions, the dominant parameters influencing the film width were examined, and it was noted that $V_{0} \sin \theta$ and $D$ influenced the film width.

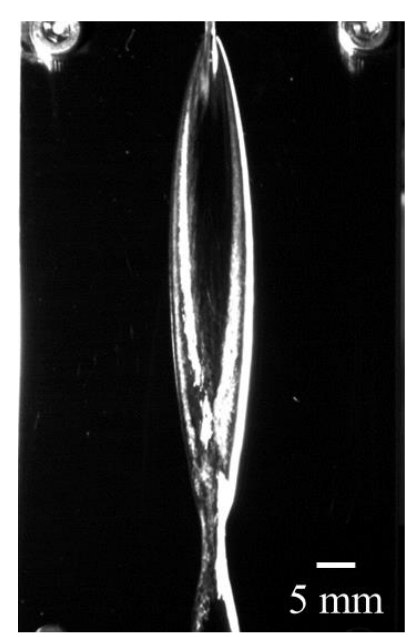

(a) $\theta=10^{\circ}$

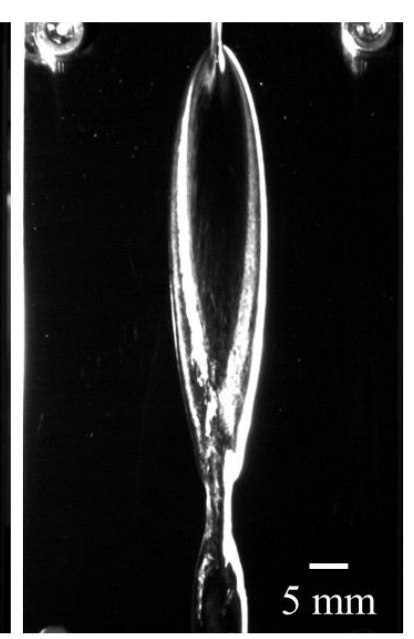

(b) $\theta=15^{\circ}$

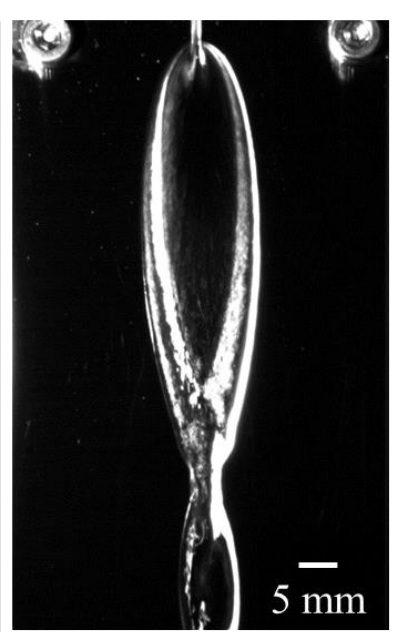

(c) $\theta=20^{\circ}$

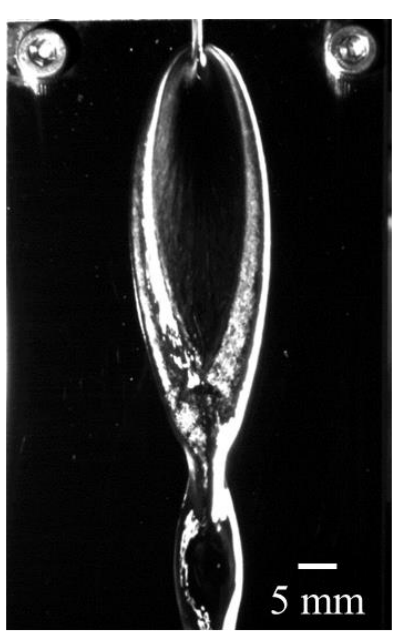

(d) $\theta=25^{\circ}$

Fig. 8 Effect of impingement angle on the film spread.

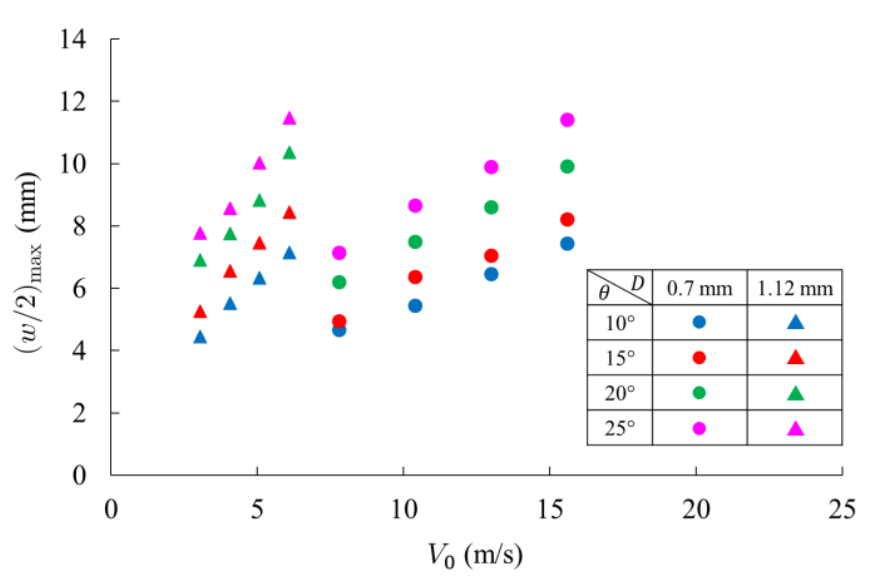

Fig. 11 Effect of impingement angle on the maximum film width.

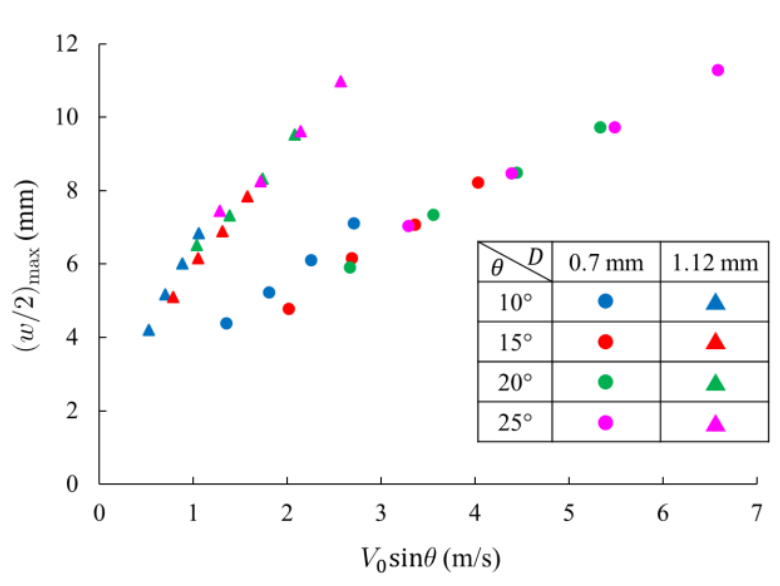

Fig. 12 Relationship between the inlet jet velocity perpendicular to the wall and maximum film width. 
As a linear relationship was noted between $V_{0} \sin \theta$ and $(w / 2)_{\max }$, it could be considered that the scale of $(w / 2)_{\max }$ could be expressed by the product of $V_{0} \sin \theta$ and the characteristic time for the film spread, as the scale of the length can be expressed in terms of the product of the scales of the velocity and time. The characteristic time scale for the film spread, $\tau_{\sigma}$, can be expressed as in Eq. (4), as determined via a dimensional analysis using the density, surface tension coefficient, and nozzle diameter, which are the key factors influencing the film width. Thus, the scale of $(w / 2)_{\max }$ can be expressed as in Eq. (5).

$$
\begin{aligned}
& \tau_{\sigma} \sim \sqrt{\frac{\rho D^{3}}{\sigma}} \\
& (w / 2)_{\max } \sim V_{0} \sin \theta \cdot \sqrt{\frac{\rho D^{3}}{\sigma}}
\end{aligned}
$$

By rearranging Eq. (5), the dimensionless maximum film width can be expressed as follows:

$$
\frac{(w / 2)_{\max }}{D} \sim \sqrt{\frac{\rho\left(V_{0} \sin \theta\right)^{2} D}{\sigma}}=\sqrt{W e} \cdot \sin \theta
$$

In addition, it can be considered that $(w / 2)_{\max }$ is equal to $D / 2$, the radius of the liquid jet, if the liquid jet impinges to the wall with $\theta=0$. Therefore, a correction term of 0.5 was added to Eq. (6), as follows:

$$
\frac{(w / 2)_{\max }}{D}=\sqrt{W e} \cdot \sin \theta+0.5
$$

All the obtained results considering the different parameters are shown in Fig. 13. It can be noted that the results under various conditions of the liquid jet velocity, nozzle diameter, and impingement angle could be uniformly organized although the data indicated a slightly shallower slope than Eq. (7). These findings indicate that the maximum film width for a liquid film generated using a single nozzle can be predicted when the injection conditions have been determined.

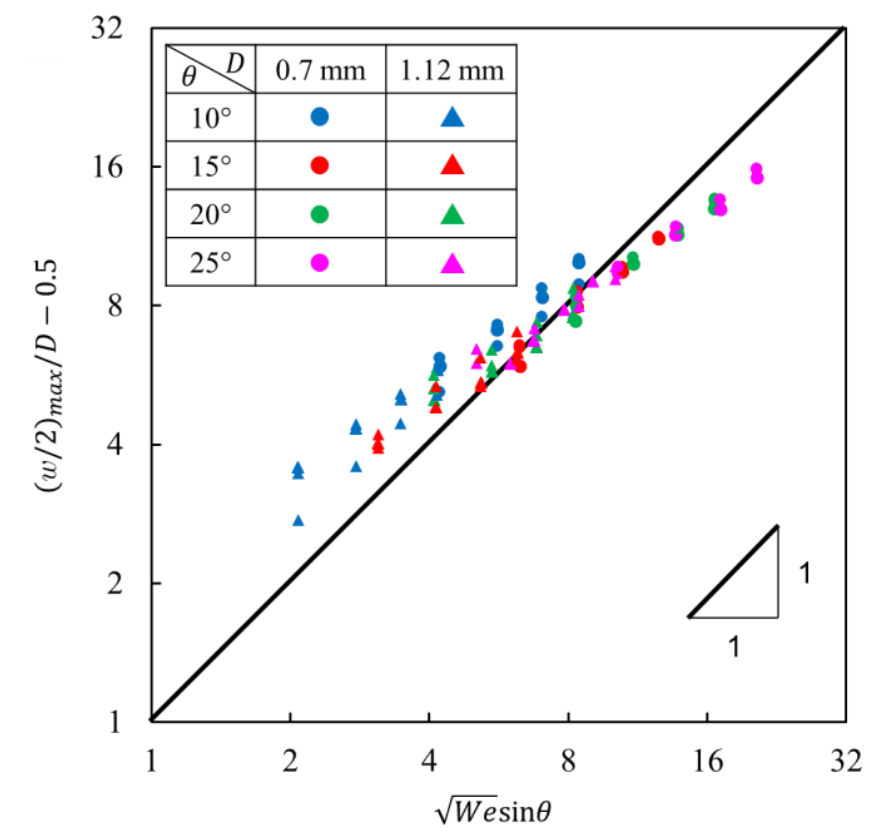

Fig. 13 Relationship between dimensionless maximum film width and the product of Weber number and $\sin \theta$ The symbols indicate the experimental data for three experimental runs in each condition. The bold line indicates the results pertaining to Eq. (7). 
Sako, Hayashi, Daimon, Tani and Kawanabe, Journal of Thermal Science and Technology, Vol.16, No.1 (2021)

\section{Conclusions}

To clarify the key factors affecting the spread of a liquid film and understand the formation process of such films, an experimental apparatus that could simulate the supply system of the fuel in actual thrusters for film cooling was developed, and experiments were performed using water as the test liquid. The mass flow rate, nozzle diameter, impingement angle, and liquid jet length were varied. It was noted that when the liquid jet velocity increased, the width and length of the film increased, and a linear relationship existed between the liquid jet velocity and maximum film width. This finding was observed at all nozzle diameters, although the slopes of the lines were different. These results indicated that the nozzle diameter was one of the factors affecting the film spread. The maximum film width increased under the same mass flow rate as the impingement angle increased, and the vertical component of the liquid jet velocity to the wall exhibited a linear relation with the maximum film width. In addition, the liquid jet length did not exert any significant effect on the film width under the experimental conditions, which were in the design range of bipropellant thrusters. Based on these results, they key factors affecting the film width were extracted, and a general relationship between the key factors and maximum film width under various conditions was identified. It was noted that the maximum film width divided by the nozzle diameter could be uniformly organized in terms of the product of the Weber number and the sine of the impingement angle, based on a dimensional analysis. These findings could provide guidance to determine the shape of an injector for film cooling, based on the physical phenomenon, instead of using a trial-and-error approach that requires experimental tests. In addition, the amount of fuel for film cooling could be optimized while ensuring a high performance and sufficient cooling of the thrusters at the same time.

In future work, the effect of the surface tension must be investigated in detail by using different test liquids. In addition, the reason why the data was not completely fitted with Eq. (7) need to be elucidated. For more accurate prediction, it is necessary to take into account the effects of the contact angle and modify the characterization parameters suitably.

\section{Acknowledgement}

We would like to acknowledge valuable discussions with Assoc. Professor Chihiro Inoue at Kyushu University.

\section{References}

Bartz, D. R., A Simple Equation for Rapid Estimation of Rocket Nozzle Convective Heat Transfer Coefficients, Jet Propul., Vol.27, No.1 (1957), pp.49-51.

Chen, X., Ma, D. and Yang, V., High-Fidelity Numercial Simulations of Impinging Jet Atomization, 48th AIAA/ASME/SAE/ASEE Joint Propulsion Conference \& Exhibit (2012), AIAA-2012-4328.

Daimon, Y. et al., Flow Field and Heat Transfer Analysis in a MON/MMH Bipropellant Rocket Engine, International Journal of Energetic Materials and Chemical Propulsion, Vol.16, Issue 3 (2017), pp.263-280.

Dambach, E. M., et al., Investigation into the Hypergolic Ignition Process Initiated by Low Weber Number Collisions, Journal of Propulsion and Power, Vol.29, No.2 (2013), pp.331-38.

Davis, S. M. and Yilmaz, N., Advances in Hypergolic Propellants: Ignition, Hydrazine, and Hydrogen Peroxide Research, Advances in Aerospace Engineering 2014 (2014), pp.1-9.

Good, R. M. and Nollet,W. K., Fluid Film Distribution Investigation for Liquid Film Cooling Application, 53rd AIAA/SAE/ASEE Joint Propulsion Conference (2017), AIAA-2017-4920.

Grant, R. P. and Middleman, S., Newtonian Jet Stability, AIChE Journal, Vol.12, No.4 (1966), pp.669-678.

Iihara, S, Miyajima, H, and Nagashima, R., Hydrazine/NTO Liquid Apogee Engine for the ETS-VI, 23rd Joint Propulsion Conference (1987), AIAA-87-1936.

Lawver, B. R. 1966, Some Observations on the Combustion of $\mathrm{N}_{2} \mathrm{H}_{4}$ Droplets, AIAA Journal, Vol.4, No.4 (1966), pp.659-662.

Lawver, B. R. and Breen, B., The Effect of Additives on Droplet Hydrazine Burning, AIAA 3rd Propulsion Joint Specialist Conference (1967), AIAA-67-482.

Matsuura, Y., Iihara, S. and Tashiro, Y., Hypergolic Propellant Ignition Phenomenon with Oxidizer Two-Phase Flow Injection, 49th AIAA/ASME/SAE/ASEE Joint PropulsionConference (2013), AIAA-2013-4154.

Morison, K. R., and Thorpe, R. J., Liquid Distribution from Cleaning-in-Place Sprayballs, Food and Bioproducts Processing, Vol.80, Issue 4 (2002), pp.270-275.

Shine, S. R., Kumar, S. S. and Suresh, B. N., A New Generalised Model for Liquid Film Cooling in Rocket 
Combustion Chambers, International Journal of Heat and Mass Transfer, Vol.55, Issues 19-20, pp.5065-75.

Stechman, R. C., Oberstone J., and Howel J. C., Design Criteria for Film Cooling for Small Liquid-Propellant Rocket Engines, Journal of Spacecraft and Rockets, Vol.6, No.2 (1969), pp.97-102.

Strutt, J. W. and Rayleigh, L., On The Instability of Jets, Proceedings of the London Mathematical Society, Vol.10, No.4 (1878), pp.4-13.

Sutton, G. P. and Biblarz, O., Rocket Propulsion Elements $9^{\text {th }}$ edition, John Wiley \& Sons.

Wang, T. et al., Flow Patterns and Draining Films Created by Horizontal and Inclined Coherent Water Jets Impinging on Vertical Walls, Chemical Engineering Science, Vol.102, (2013), pp.585-601.

Weber, C., On the breakdown of a fluid jet, Z. Angew. Math. Phy., Vol.11, (1931), pp.136-159

Webber, W. and Hoffman, R., A Mechanistic Model for Analysis of Pulse-Mode Engine Operation, AIAA SAE 8th Joint Propulsion Specialist Conference (1972), AIAA-72-1184.

Wilson, D. I. et al., Surface Flow and Drainage Films Created by Horizontal Impinging Liquid Jets, Chemical Engineering Science, Vol.68, Issue 1 (2012), pp.449-460. 